\title{
Moral Judgment Test (MJT) in Urdu: Translation and Validation
}

\author{
Abdul Wahab Liaquat (Islamabad, Pakistan)
}

In moral Psychology a comprehensive theory of cognitive moral development is given by Lawrence Kohlber that describes an individual's movement through three levels of cognitive development named as pre-conventional, conventional and, postconventional levels of moral development. These three levels consist of six sub stages. The pre-conventional level (representing stage 1 and 2) suggests egocentric morality where individuals decide on moral problems on the basis of immediate -pleasant or unpleasant -- consequences produced by the actions of individuals themselves or those of the others, or by the instrumental utility of these actions. At conventional level (representing stages 3 and 4), the focus shifts from self to society and usually social desirability is the main reason behind ethical decision making; the conventional level culminates at stage 4 that is dominated by a rigid rule obeying mentality, where social rules are considered as sacred entities that ought not to be violated even in exceptional situations. The post-conventional level (representing stages 5 and 6) is the development of more flexible view about social rules and society in general. Social rules and laws are not considered as sacred entities but as situational necessities that are prone to change through democratic means (stage 5), or as the final stage of moral development (stage 6) suggests, can be challenged when these contradict with some basic universal human values (Colby, and Kohlberg, 1987).

Kohlberg also devised an interview method called the "Moral Judgment Interview (MJI)" to assess an individual's level of cognitive moral development that involved presentation of dilemma situations to the participants and an intensive probing to assess their level of moral reasoning (Colby \& Kohlberg, 1987). Another 
quantitative measure of moral reasoning based on Kohlberg's stages of moral development was developed by James Rest (1979, as cited in Lind, 2008) called the Defining Issues Test (DIT). The DIT is a very handy tool as it's a paper pencil test with ease of administration on a larger sample as compared to MJI that requires special expertise on the part of the interviewer.

Moral Judgment Test (MJT) is another instrument developed by Georg Lind (1978) to measure level of cognitive moral development termed as moral judgment competence. The MJT contends with the procedure adopted in both Moral Judgment Interview and Defining Issues Test. The author of the MJT claims that the Moral Judgment Interview does not actually measure cognitive component of morality independent of affective component and gives mixed indices while DIT only measures moral attitudes and does not measure moral judgment competence at all (Lind, 2008, p. 208). Instead, Lind is of the view that moral development takes place simultaneously in both cognitive and affective domains. The two aspects are parallel and inseparable and a theoretically good instrument needs to have the ability to measure both aspects simultaneously so one aspect may not confound with the other (Lind, 1985, 2008).

He distinguishes the cognitive structural aspect of moral development form the content aspect by defining it as, "the structure of moral judgment behavior reflects the organization and process of moral thinking, the way in which and the degree to which moral maxims or principles are brought to bear in specific situations" (Lind, 1985, p. 21). This definition shows that structural aspect represents some rules of thinking that are applied on some affective contents which are based on moral maxims and moral principles (p. 22). This approach is very much closer to what Kohlberg actually intended to describe when he defined moral judgment as "the capacity to make decisions and judgments which are moral (that is based on internal principles) and to act in accordance with such judgment" (Kohlberg, 1964, as cited in Lind, 1985, p. 22).

Lind (1985) suggests that Moral Judgment Interview only partially measures moral judgment consistency while DIT can only assess on what stage of moral development an individual is standing and both of these methods fall short of measuring moral judgment competence (p. 207-209).

The Moral Judgment Test instead, covers up, and supplements the weaknesses of the previous methods and -- as Lind claims -- measures the same construct what Kohlberg actually wanted to measure, with more accuracy and precision. MJT is an Experimental Questionnaire that has different psychometric properties than other tests or attitude scales based on classical testing theories (Lind, 1982, p. 14-16). The test is a multivariate $\mathrm{N}=1$ experiment with a $2 \times 2 \times 6$ factorial 
design, which consists of two moral dilemmas in the form of two very brief stories (a euthanasia dilemma and a workers' dilemma); each dilemma provides an artificial but a real life situation on which a decision is made by the characters of a story and participants have to rate how much they agree with the solution on a 7 point scale (3 to +3 ). After each moral dilemma six arguments in favor of that solution and six arguments against that solution are presented (the arguments actually represent Kohlberg's 6 stages of cognitive moral development) and participants have to rate the degree of acceptance or rejection of these arguments on a 9-point scale $(-4$ to +4$)$. A multivariate analysis of variance is used to obtain two types of scores (Lind, 1986, p. 5, 2000a).

1. Attitude scores that represent the affective component of individual's moral thinking which is calculated as the sum total of sum of four scores for each moral stage of reasoning. These scores are individual's stage preferences that tell which stage of reasoning is the most and/or the least preferred by the individual.

2. C-index (or c-scores) which is the distinguishing feature of MJT represents the cognitive component of an individual's moral thinking also called moral judgment competence. The c-index reflects how much consistently certain stages are preferred by the individual. High c-scores usually result when an individual consistently rates arguments whether in favor or against his opinion by assessing the moral quality of each argument. Low c scores usually result from inability to understand responses representing the same stages, or because of opinion agreement, or simply obedience to authority.

The Moral Judgment Test is a unique measure as it does not contain the classical psychometric properties and is devised to predict the assumptions of cognitive developmental approaches/theories of morality. Usually 3 criteria are described on which such an instrument needs to be tested in order to make claim about its validity. The test has been translated into 29 languages across the world and proved to be cross-culturally valid on the following criteria (Lind, 2008, p. 212).

1. Preference hierarchy: The Kohlbergian stages are preferred in a theoretically predicted manner, i.e. the highest stages are preferred the most, the lowest stages are preferred the least, and the stages in between are moderately preferred. (Lind, 2008, p. 203) 
50 I Abdul Wahab Liaquat

2. Cognitive-affective parallelism: C-scores have a significant negative correlation with preference scores for lower stages and have a significant positive correlation with higher stages (p. 203)

3. Quasi-simplex structure: The neighboring stages correlate higher with each other and have low correlations with more distant stages, i.e. stage 1 and 2 correlate higher with each other than stage 5 and 6, while stage 3 and 4 come in between higher and lower stages (p. 203)

The present study aimed to validate a new MJT version into Urdu language for Pakistani population according to the above mentioned criteria. This validation study was conducted as part of the larger study that aimed to find out differences of moral judgment competence and moral preferences between students of Public and Private sector Colleges and Universities, and students attending Madaaris (Islamic religious Institutes) in Pakistan. The study also aimed to determine the pattern of development of moral judgment competence within these educational institutes by comparing the level of moral judgment competence of students in their first years of admission with students in the terminal years at the time of completion of their courses ${ }^{1}$.

\section{Methodology}

For the translation of MJT English into Urdu language, Brislin's translation method with some modifications was adopted (as cited in Willgerodt, Kataoka-Yahiro, Kim, and Ceria, 2005: p. 231-233). The test was translated into Urdu language by the author of the present study and was blindly back translated into English by a bilingual English language lecturer and an English language Assistant Professor at Government Postgraduate College Asghar Mall, Rawalpindi. The translated and back translated versions were assessed by a PhD. Associate Professor of Psychology at International Islamic University, Islamabad. Certain modifications were made in the Urdu language version that was again back translated into English.

A pretest study was conducted on a small sample $(\mathrm{N}=10)$ of $7^{\text {th }}$ grade students. Certain lingual difficulties were noted related to the comprehension of difficult words and terms. A modification was made in the argument No. 8 of "workers' dilemma" as the exact equivalent of the word "universal" in Urdu was

\footnotetext{
1 The study is in progress yet.
} 
not comprehensive for the students and it was replaced by an easier sentence that translated as "on which there is a consensus of all people". Also two words "official things" were inserted before the words "property ownership" as it was noted that participants were not able to relate the argument with the theme of the story. Participants reported much difficulty in comprehending the sentences at the beginning of pro and contra arguments. More explanation was added at the beginning of stage arguments in order to clarify the whole concept. Instead of the statement in the English version, "How acceptable do you find the following argument in favor of the two workers' behavior? Suppose someone argued they were right ...", the beginning statement in the Urdu version modified to look like this, "Let's suppose someone says that the workers did the right thing (or "did the wrong thing" for contra arguments) to steal the tape recording, and for this, if that person gives some arguments then how much would you agree with those arguments? Suppose that the person gives, the following arguments that workers were right ("wrong" for contra arguments) in stealing the tape recording...". This pattern was repeated in all four places before stage arguments. Participants reported much better comprehension with this explanatory pattern than the pattern used before similar to the one used in the English version. After going through these steps of translations, back translations and making certain slight modifications the test appeared to be good enough to use on a larger sample.

\section{Sampling strategy}

The study was conducted in two phases. A sample from Public sector schools and colleges was collected during the first phase of the study and due to very low mean c-scores found in the whole sample an additional sample of university students was collected later at the second phase of the study.

\section{Phase I}

\section{Sample and test administration}

During the first phase of the study, a sample of 200 participants, (males $54.5 \%$, females $45.5 \%$ ) ranging from $8^{\text {th }}$ grade to $16^{\text {th }}$ grade was selected from four different public sector schools and colleges; (a sample of boys of grade 8 to 10 was selected from Government Boys High School, DAV College Road, Rawalpindi and girls were selected from Government M. C. Girls High school, Satellite Town, Rawalpindi). Girls of grades 11, 12 and 13 were selected from Government Degree College for women, B-Block, Satellite Town, Rawalpindi, and boys of grade 12 and 13 were selected from Government Postgraduate College, Asghar Mall, Rawalpindi. A 
sample of $16^{\text {th }}$ grade (i.e. MA Economics) students, both male and female, was selected from Govt. Postgraduate College, Asghar Mall, Rawalpindi. Test forms were administered in the class rooms of the respective institutes to the students who volunteered themselves for the study. Uniform instructions were used for all of the participants which included description of the purpose of research and explanation of the method to fill the test. No time restrictions were placed on the participants. Out of 200 test forms 18 incomplete forms were dropped from the analysis (other 22 forms that were analyzable but incomplete were not included in the first analysis, they were however included in the second phase of the research). Data of 160 participants were selected for the analysis. The sample was composed of 160 participants (males $62.5 \%$, females $37.5 \%$ ), ranging from 13 to 25 years of age $(\mathrm{M}=$ $17.47, \mathrm{SD}=2.855)$, with grade distributions as grade $8(\mathrm{~N}=23,14.4 \%)$, grade $10(\mathrm{~N}=$ $39,24.4 \%)$, grade $11(\mathrm{~N}=14,8.8 \%)$, grade $12(\mathrm{~N}=20,12.5 \%)$, grade $13(\mathrm{~N}=34,21.3$ $\%)$, and grade $16(\mathrm{~N}=30,18.8 \%)$. The data set was send to the author of the original version of the $\mathrm{MJT}^{2}$ for further analysis.

\section{Results}

The data analysis showed very low c-scores for the whole sample $(\mathrm{M}=13.60, \mathrm{SD}=$ 9.05). This trend was noted irrespective of grade levels and across all institutions. Grade wise comparison of c-scores shows almost a flat curve (Figure 1) with no significant differences between groups according to level of education, $F(5,154)=$ $1.780, p<.120$.

The sample information was assessed on three standard criteria for validation.

1. Preference Hierarchy: A repeated measure ANOVA analysis indicated that there were differences between the average ratings for the six stages, $F$ (5, $795)=32.81, p<.000$. The preference hierarchy did not appear very clearly when whole sample was analyzed with slight differences between means (Figure 2). Howere as Figure 3 shows when only data of college students were analyzed the hierarchy emerged more clearly showing validity of the test on this criterion.

2. Cognitive-Affective Parallelism: The average correlation values between cscores and stage scores for each participant are not significant (Figure 4). It is noteworthy that though the correlations are not significant the c-scores show

\footnotetext{
${ }^{2}$ Georg Lind, Department of Psychology, University of Konstanz, Germany. Data analysis for this study was done by Georg Lind except segmentation analysis shown in this article which was done by the author of the present study. All graphs shown in this article are provided by Georg Lind.
} 
negative correlations lower stages (Stage 1, $r=-.102$, and Stage 2, $r=-.030$ ) and show significant positive correlation with stage $5(r=.243, p<.01)$. As the means c-score of the sample was very low such correlation values were expected due to low variance in the whole sample.

3. Quasi-simplex Structure: Principle component analysis with varimax rotation was conducted to assess the theoretically predicted stage structure. The first component, loads most strongly the Stage 1, all other stages have strong loadings on second component. The pattern shows that stage 5 and 6 correlate highly with second factor and both stages are quite distant from stage 1. Stage 2 also has some loading on first component but it has stronger loading on component 2 which is not ideal (Figure 5).

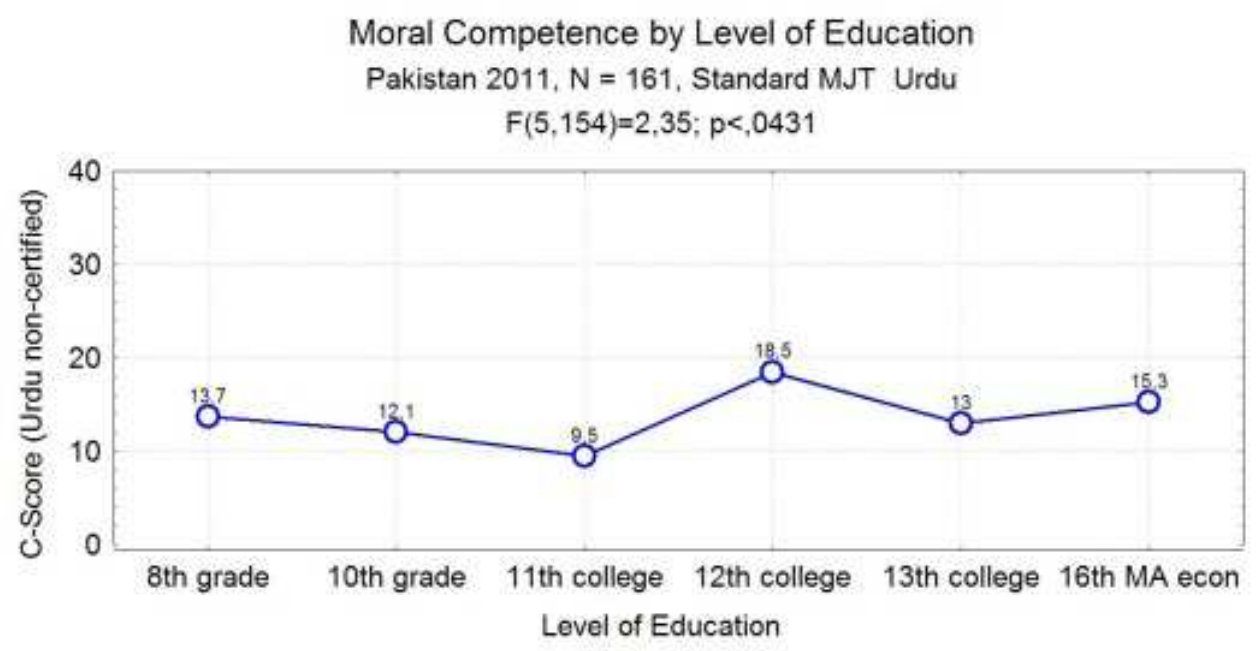

Figure 1. Comparison of mean c-scores of $8^{\text {th }}$ to $16^{\text {th }}$ grade students. A relatively flat curve shows low mean c-scores across grades (Mean $=13.60, \mathrm{SD}=9.05$ ) 


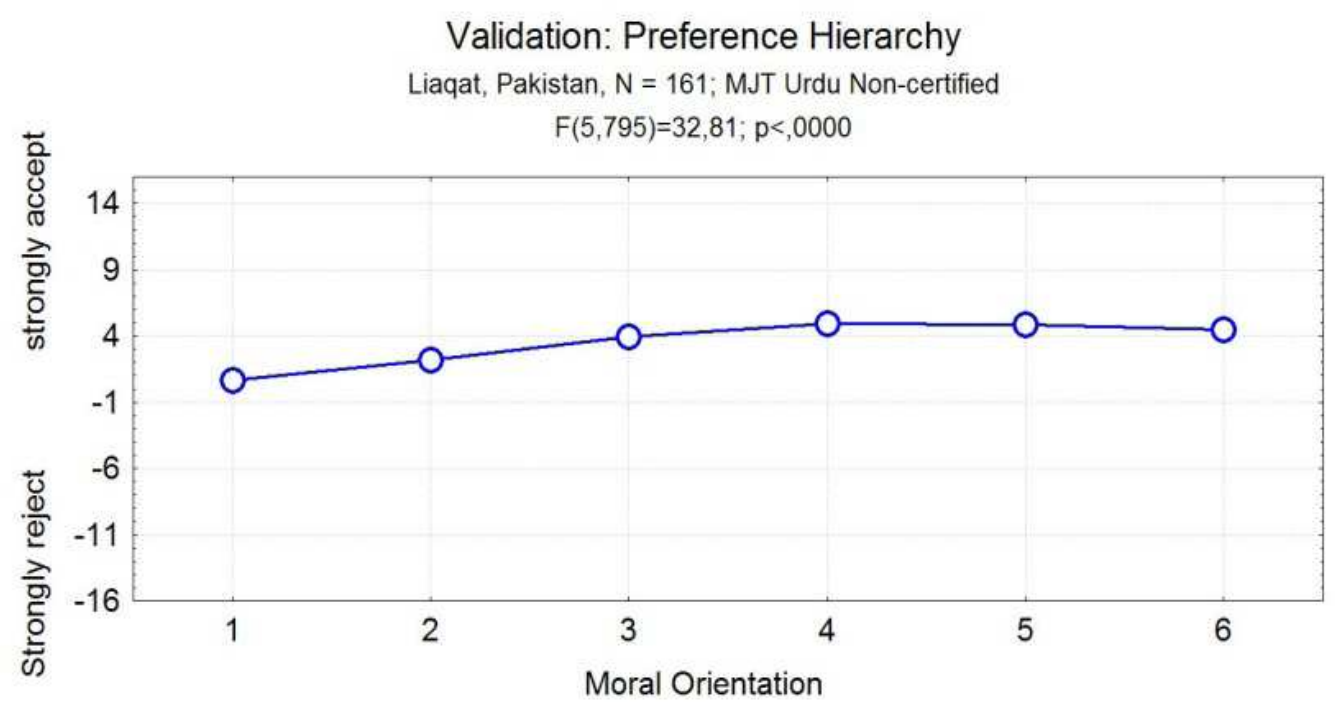

Figure 2. Mean differences between stage preference scores. The differences are significant but the curve is much flatter due to low mean scores for all stages

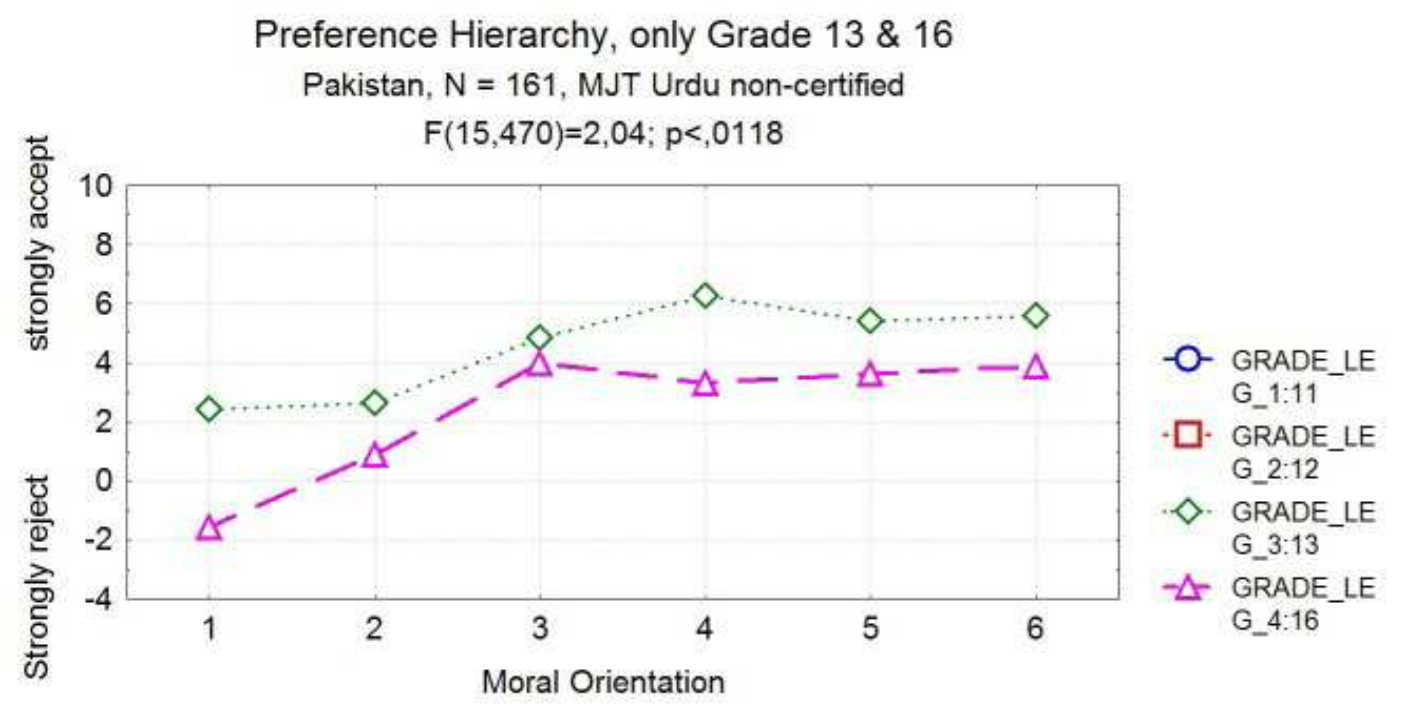

Figure 3. Analysis done on college sample to determine mean differences of stage preference scores. Students of grade 13 and 16 are showing an orderly increasing preference for higher stages of moral development with slight deviation at stage 4 by grade 13 and at stage 3 by grade 16 students. 


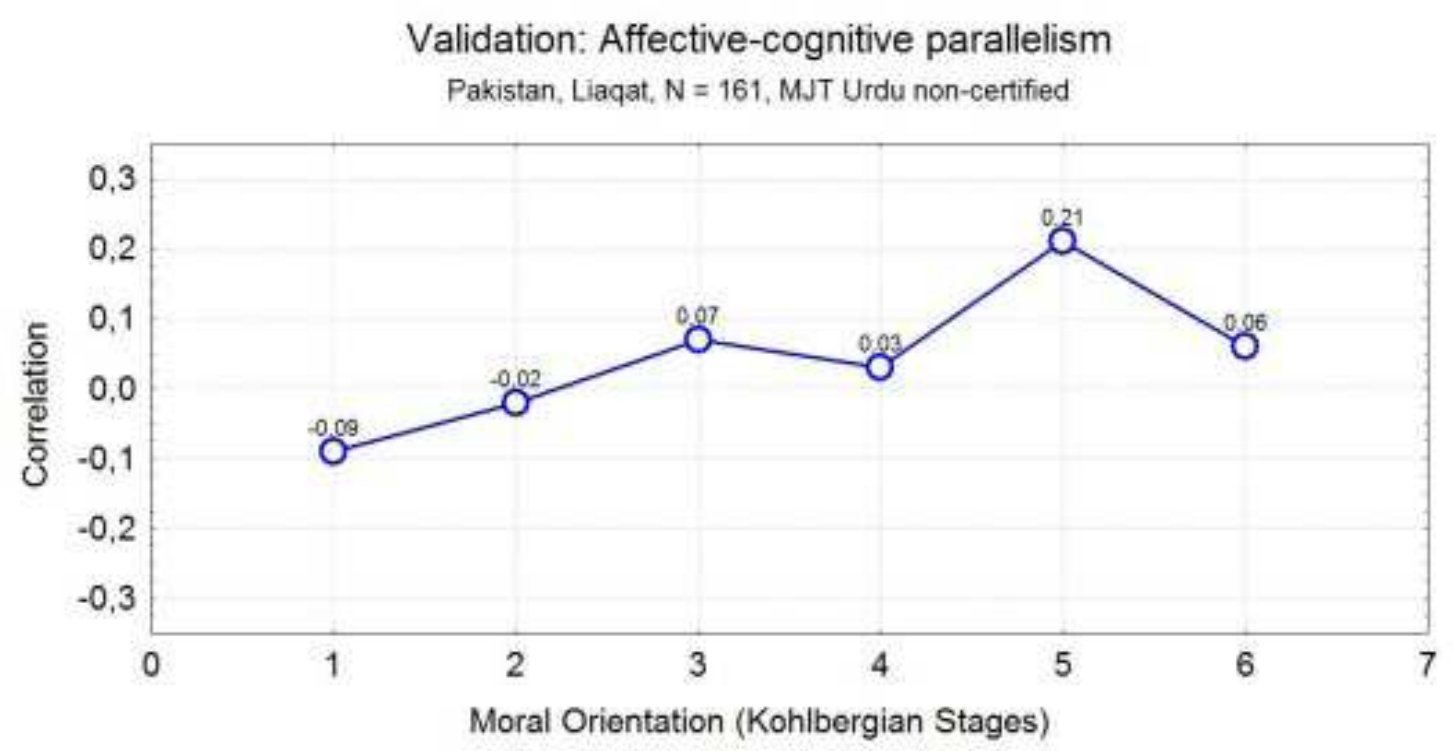

Figure 4. Correlation between c-scores and stage scores. The correlations are not significant.

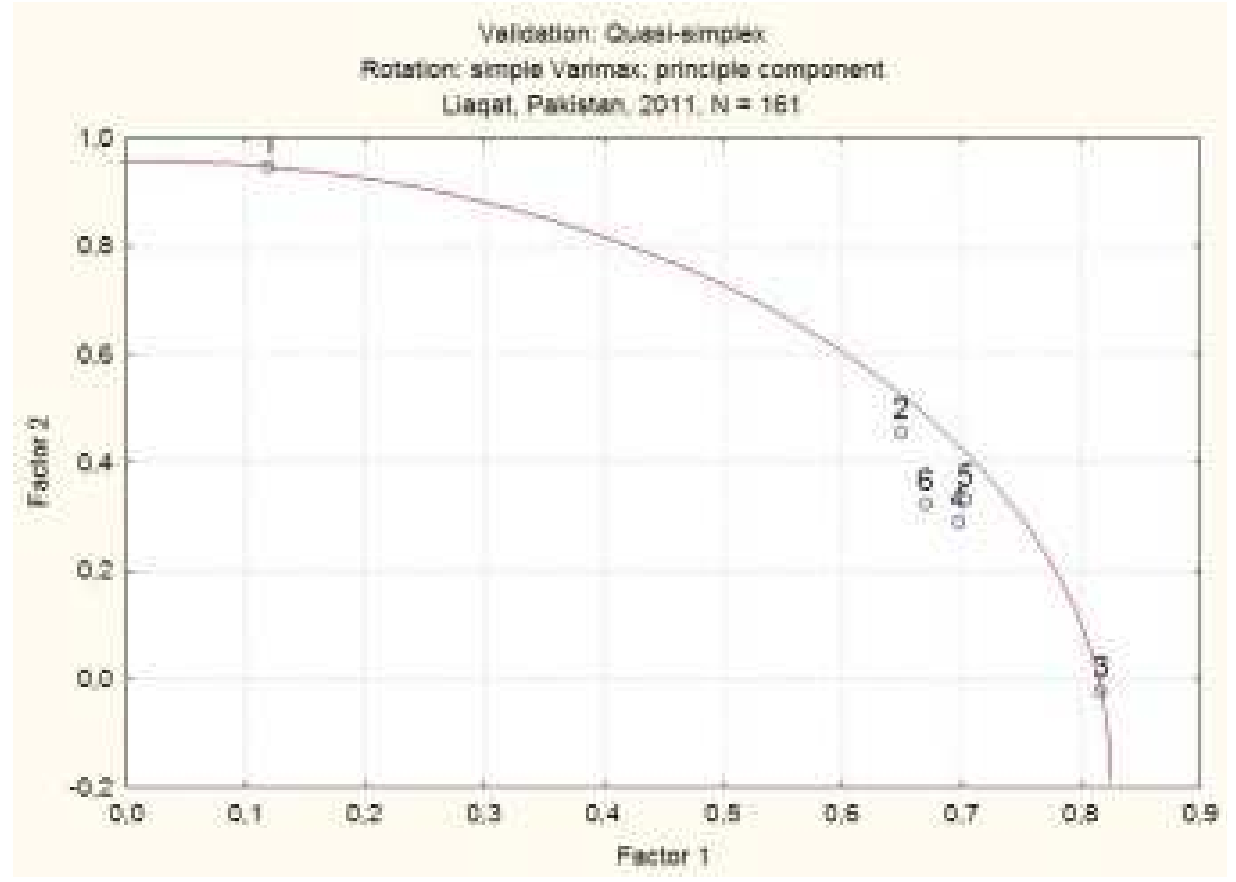

Figure 5. Principle component analysis with varimax rotation. The simplex structure is not ideal with stage 3 extremely dislocated. 
As the test was well fitted on the preferences hierarchy criterion, but the sample had very low mean c-score, the other two criteria remained to be inconclusive. Another sample was planned to be collected from students getting higher education (i.e. grade 15 and above) from universities that were supposed to provide relatively better education in comparison to public sector schools and colleges.

\section{Phase II}

\section{Sample and test administration}

As the mean c-score of the first sample was very low another sample from 3 universities with better educational environment was obtained. Following the ranking methodology of Higher Education Commission Pakistan (HEC) ${ }^{3}$, three universities (two public sector and one private sector university) from the top 10 ranked universities were selected and a sample of 64 students (males $57.8 \%$, females 42.4\%) was collected. A total of 31 participants (48.4\%) doing MA (i.e. grade 15 and 16) were selected from the philosophy department of the University of the Punjab, Lahore. From the faculty of business administration of Lahore University of Management Sciences (LUMS), which is a private sector university, 17 participants (26.6\%) of either studying in MBA or in BS Honors last year (grade 16) were selected, 16 participants (25\%) of M.Sc. (grade 16) or MS (grade 18) were selected from Psychology and Media Studies departments of International Islamic University, Islamabad. The selected students volunteered for the study and the same instructions were used as described in the phase I of the study. The data set was analyzed as a whole including the new and the old sample plus missing data that was not analyzed in the first phase of the study.

\section{Results}

The c-scores in the new analysis with broader sample did not improve even with the inclusion of data from top ranked universities of Pakistan $(M=13.94, S D=9.53)$. No significant cross institutional difference in mean c-scores was observed, $F(6,224)=$ $2.67, p<.0159$ (Figure 6).

The analysis on the broader sample showed results quite identical with the first phase of the test on the standard criteria of test validation.

1. Preference Hierarchy: The repeated ANOVA analysis showed that participants differed in stage ratings, $F(5,1155)=39.68, p<.000$, and the mean scores for

\footnotetext{
${ }^{3}$ Higher Education Commission, Islamabad, Pakistan; a ranking criterion can be seen from this link http://www.hec.gov.pk/insidehec/divisions/qali/others/rankingofuniversities/pages/Default.aspx
} 
stages showed a clear orderly preference for the stages from lower to higher as predicted by the theory. A bit flatter curve appeared again due to low cscores of the sample (Figure 7).

2. Cognitive-Affective Parallelism: The correlation value for the broader sample did not come out to be significant. Though the correlation pattern, as Figure 8 suggests, still showed that c-scores significantly positively correlated with stage $5(\mathrm{r}=.285)$ and stage $6(r=.192)$ and correlated negatively with stage 1 $(r=-.055)$ due to lower mean c-score of the whole sample it was difficult to determine the cognitive-affective parallelism criteria effectively.

3. Quasi-simplex Structure: The broader sample showed somewhat high loading of stage 2 on first factor but still stage 2 correlates higher with second factor. Stages $3,4,5$, and stage 6 , load strongly on second factor with stage 3 looking to be more problematic as it loaded most strongly on the second factor instead of showing its loading on both factors as required by the standard criteria (Figure 9).

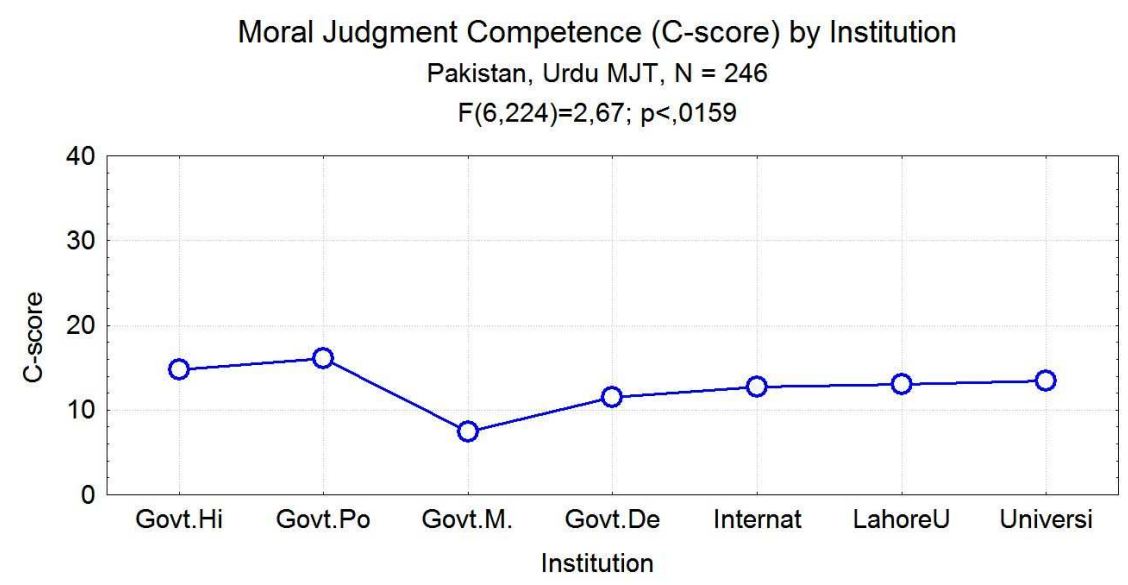

Figure 6. Institutional comparison of c-scores for the larger combined sample of the two phases of the study. A flatter curve showing very low c-scores of the students of all institutes $(M=13.94, S D=9.53)$. 
58 I Abdul Wahab Liaquat

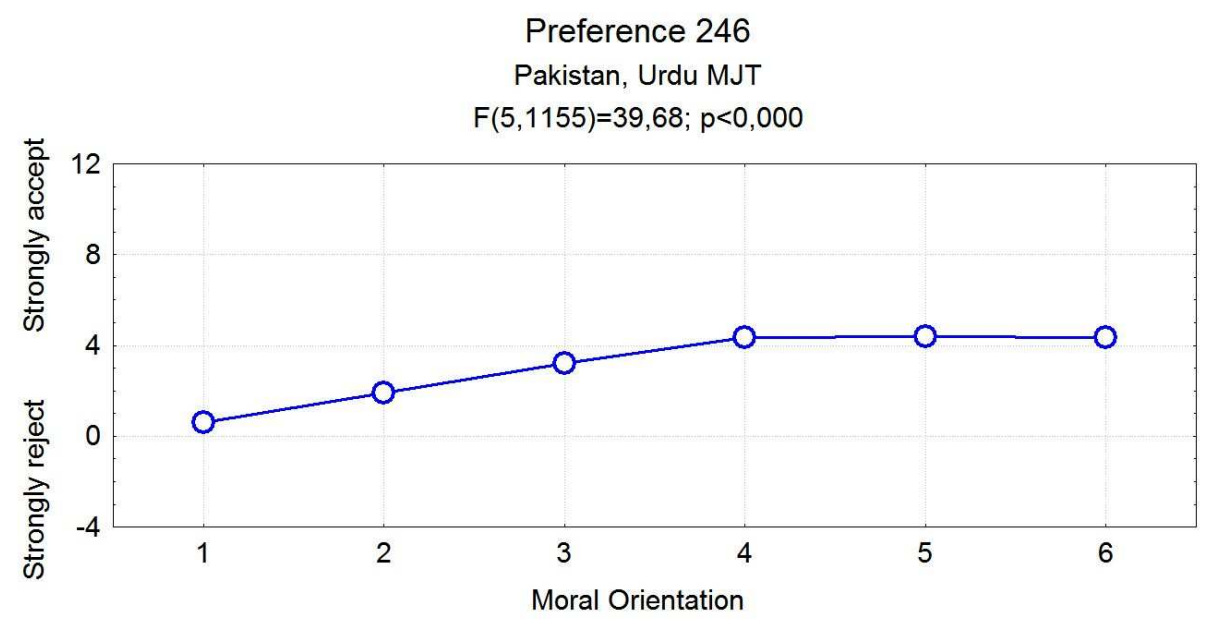

Figure 7. Comparison of mean preference scores for the larger sample. The means scores show theoretically required orderly preference for lower and higher stages of moral reasoning.

Paralellism 246

Pakistan 2011, Urdu MJT

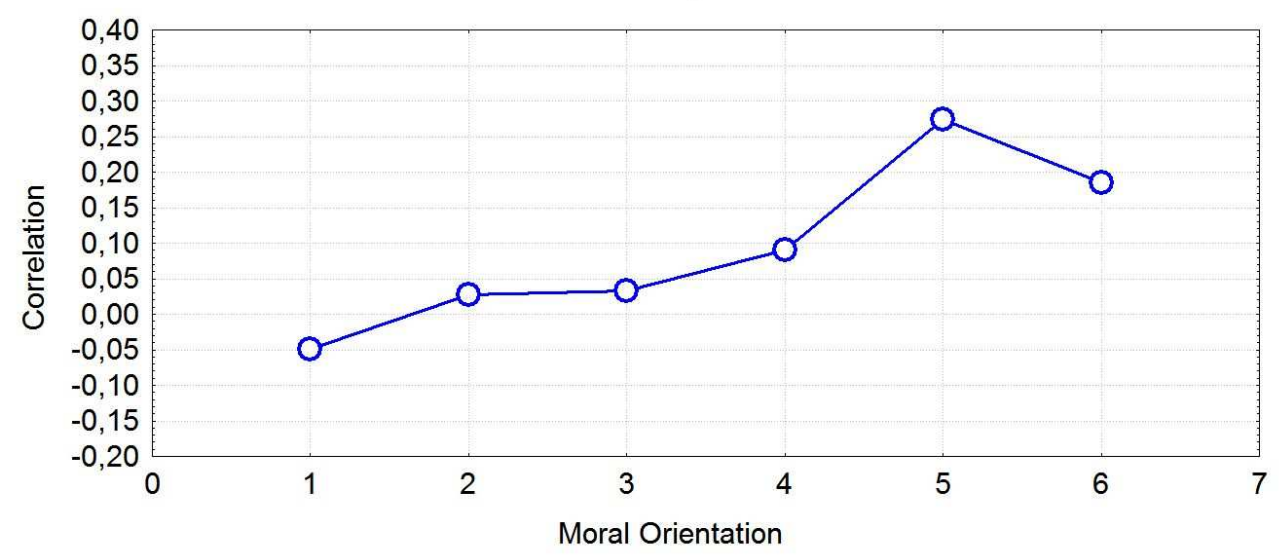

Figure 8. Correlation between c-scores and preference scores on stages of moral reasoning. The correlations are not significant. 


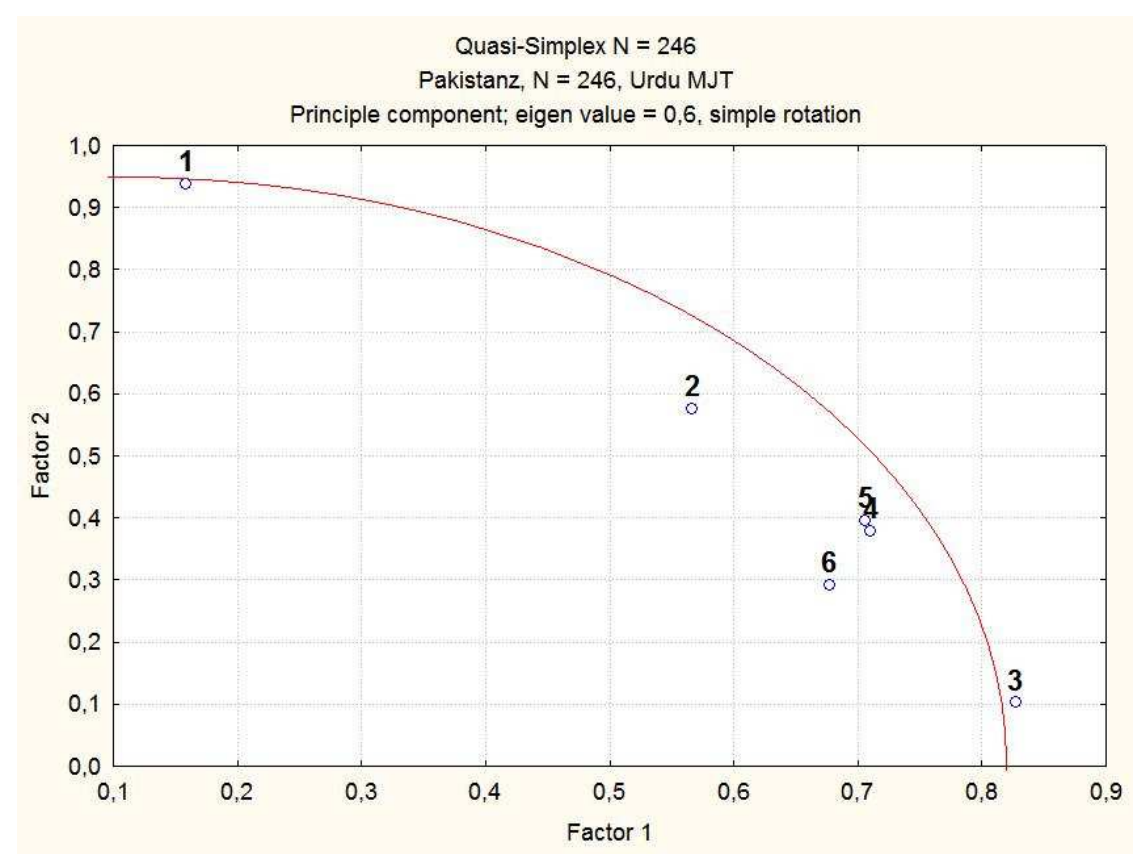

Figure 9. Principle component analysis with varimax rotation. Quasi simplex structure is not ideal as predicted by theory with stage 3 extremely dislocated.

\section{Segmentation Analysis}

Additional analysis was done in order to measure moral segmentation scores. Moral segmentation means that "subjects apply a different level of moral judgment competence when deciding on different moral issues" (Lind, 2003). Paired Sample ttest analysis showed a significant differences between c-scores on two dilemmas, $t$ $(245)=7.193, p<.000$, with mean difference -13.29 between the two dilemmas (Workers' dilemma, Mean $=38.11, \mathrm{SD}=21.43$; Doctors Dilemma, Mean $=24.81, \mathrm{SD}=$ 20.92).

\section{Discussion}

The results depict that the test is valid only on the preference hierarchy criterion which suggests that individuals are showing discrimination for the six moral developmental stages in the Urdu translated version in a theoretically predicted order. The most important finding that makes it difficult to conclusively detect validity on the other two criteria is low mean c-score for the whole sample. The low c-scores do not provide enough variance to establish validity on the cognitiveaffective parallelism and quasi simplex structure criteria. Though the correlation 
pattern -- in cognitive-affective parallelism criterion -- between stages of moral reasoning and c-score is quite like theoretically required, the correlations are not significant enough to make a final statement. Following tentative conclusions are drawn from the present study on the basis of very low mean c-score of the sample.

Today we know that moral judgment competence is enhanced by ample opportunities of role taking and guided reflection while educational environment that does not promote autonomous critical thinking leads to stagnation, even, regression in moral judgment competence (Lind, 2000b, p. 11-13, 2000c, p. 14-15, Lupu, 2009). Pakistani educational system does not appear to foster these competencies. A thorough analysis of the quality of higher secondary education in Punjab Province of Pakistan by Shahzad (2007), showed that secondary and higher secondary educational institutes in Punjab lack even such basic facilities as qualified teachers, quality text books, furniture, drinking water, and proper class rooms. The curriculum looks to be out-dated that does not contribute to the development of independent thinking in students; the teaching methodology is not very constructive and engaging and only lecture method is considered to be most effective with minimal participation of students (p. 145, 152).

Poor quality of instructional methods is also reported by another study on the sample form Pakistani universities (Iqbal, 2004). The study shows that Pakistani public sector universities are not up to the mark as far as the development of faculty and staff is concerned. Teachers mostly use lecture method, and discovery, and other participatory methods are not encouraged; even inside universities, rote learning is usually common to get success in exams. Emphasis is not put on character building and moral education of university students, and there is a gap between academic research work and its practical utility (Iqbal, 2004. p 278-279). On the basis of such findings it can be argued that poor teaching methodologies, and low quality education, in public sector schools, colleges, and universities, are possibly hampering students' critical and autonomous thinking abilities which in turn could become a possible factor in low moral competence in students of all grades in Pakistani sample.

A study by Lupu (2009) in Romania suggests that moral judgment competence is negatively related to dogmatic religiosity and even opportunities of role taking and guided reflection do not contribute much in the development of moral judgment competencies in highly dogmatic groups. Saeidi-Parvaneh (2011) reported similar findings for Iranian students, his study shows that not only dogmatic religiosity hampers moral competence, but also, highly religious social context leads to another phenomenon called "moral segmentation" which is described as getting significantly low c-scores on a dilemma for which strong 
religious dogma exists (commonly euthanasia dilemma in MJT) as compared to the other dilemma that is less religiously concerned (commonly workers' dilemma in MJT). Bataglia and Schillinger-Agati (2002, as cited in Schillinger-Agati \& Lind, 2003, p. 4-6) compared c-scores of subjects who were highly committed to religion with those who were not at all committed to religion in a Brazilian sample. The results of the study showed no significant difference between two groups. The authors concluded that some "cultural" phenomena were also contributive to the development of moral segmentation instead of submission to Church authority alone. This cultural phenomena they termed as "Orthodoxy" which refers to more conservative, external divine oriented approach toward moral problems as compared to "Progressivism" that suggests more liberal, self-directed and autonomous view toward solution of moral problems.

The results of the present study show the similar pattern. The overall c-scores are very low irrespective of the level of education, and segmentation analysis showed that participants got significantly low c-score on euthanasia dilemma than on workers' dilemma, with mean difference of -13.29. This moral segmentation may be due to religious structure of Pakistani society. Pakistan as an Islamic republic can be considered as a society of deeply religious people (in a dogmatic sense) as it was founded with the intention to implement Islamic principles in it and to provide an opportunity to the Muslims of Indian subcontinent to live according to Islamic values. Though, in Pakistan, Islamic Sharia Law is not implemented in a true sense and most of the law making is based on Anglo-Saxon principles, the laws do not contradict the basic tenets of Islam. The constitution of Pakistan declares that, "all existing laws shall be brought in conformity with the injunctions of Islam as laid down in the Holy Quran and Sunnah, in this part referred to as the injunctions of Islam, and no law shall be enacted which is repugnant to such injunctions" (The Constitution of Pakistan, 2010, Part IX, article 227-1). Pakistan's political history shows a constant struggle between competing secular socialist and dogmatic religious ideologies whether in the form of politicians or military men (Khalid, 2004). According to Khalid, the Islamic fundamentalism especially got stronger roots during the reigns of Zulfiqar Ali Bhutto and Gen. Zia ul Haq between the early 70s to late 80s. Bhutto introduced a kind of "Islamic socialism" in Pakistan, "He announced Islamic reforms, banned liquor shops, gambling, horse racing, and night clubs ..." (p. 276). He also declared the Ahmadis as non Muslims and reduced their constitutional rights by making them a minority sect (p. 276-277). Gen. Zia-ul-Haq, Bhutto's successor, also came with an Islamic agenda and made alliance with Islam Pasand (Pro Islamic) parties. He exploited these situations well due to conditions in Afghanistan to counter USSR forces when, " the CIA (Central Intelligence Agency) 
and the ISI (Inter Services Intelligence) trained thousands of Pakistani and Arab volunteers to become diehard Jihadis, an amalgam of both homicidal and suicidal tendencies and viciousness" ( $p$ 278). His policies lead to rise of fundamentalism in Pakistan and especially religious schools (madaris) of Wahabi and Deobandi sects irregularly spread throughout the country that became the root cause of sectarianism and intolerance. His policies also lead to strife between Shia and Sunni sects of Pakistan whose impact is still visible today (p. 279).

The present scenario in Pakistan is not much different than what is explained, as Pakistan is a huge victim of terrorism and extremism today especially after 9/11 incident of terrorist attacks in the U.S., the situation is well aggravated. The present state of affairs gives us a good evidence to assume that the low c-scores on MJT-Urdu version and moral segmentation scores are reflecting the basic value structure of Pakistani society where fundamentals of religion are given core importance in day to day decision making and even if some people do not actively follow these fundamentals, still they have to confirm to these values in order to maintain a social cohesion.

The third possible explanation for the low c-scores on MJT-Urdu version can be found in the political structure and political history of Pakistan. A seven year longitudinal cross sectional study from 1977 to 1983 conducted in Austria, Germany, the Netherlands, Slovenia and Poland (Bargel, Markiewicz, and Peisert, 1982, as cited in, Nowak, and Lind, 2007) showed quite dissimilar trends in the moral competence scores between the democratically ruled German sample and a sample from politically instable and mostly autocratic Poland. The Polish sample showed a sudden increase in c-scores during the period 1977-1979 and then a sudden decrease during the period 1979-1982, in contrast, the German sample showed a steady increase in moral competence scores during that time period. The authors explain this phenomenon on the basis of political changes taking place during that time period in Poland. The authors argue that the first three years of sudden improvement in c-scores in a Polish sample show the democratization of government system during that time while the next years of reversal in c-scores can mainly be explained by the coup d'état by military in Poland that severely damaged the democratization process (p. 9). Following this line of argument it can be hypothesized that low moral judgment competence of students is a result of politically instable structure of Pakistani society. Pakistan is a country where there has been a consistent see-saw struggle between military officials and politicians to grab the power. Three martial laws have been imposed right from its early years of creation i.e. from 1958 to 1985, while in between 1999 to 2008; Pakistan remained under direct military rule without a declared martial law. Pakistan is usually 
considered as a military run country where democratic governments remain fragile and under the thumb of stronger and well organized army. According to Inayatullah, and Inayatullah (1997)

Due to the domination of state institutions over political institutions, Pakistan has not experienced a steady consolidation of democracy over its fifty year history. This is manifest in the lack of roots of constitutionalism, the absence of fully autonomous judiciary, a well developed party system and regularly held fair elections.

The decision making theory (as cited in Nowak, and Lind, 2007) assumes that limitations in the social and political environment disturbs the decision making process that ultimately leads to indecision, inconsistency and resignation (p. 15). As the Pakistani political system permanently remained out of shape, it is very reasonable to assume that its weak political structure is affecting its residents in many ways and possibly low moral judgment scores are one of these indications.

I am extremely thankful to Professor Dr. Georg Lind (University of Konstanz, Germany) for providing me guidance throughout this study and for doing all the data analysis. I am indebted to Professor Dr. Anis-ul-Haq (Quaid-e-Azam University, Islamabad, Pakistan) for helping me in data analysis for myself and helping me in many other ways. I am also thankful to Professor Dr. Syed Asghar Ali Shah (International Islamic University, Islamabad, Pakistan) for helping me doing translation of the test and also to Professor Irfan Yawar and Rashid Zia (Lecturer) from Government Postgraduate College, Asghar Mall, Rawalpindi, for doing back translations of the test.

\section{References}

Collby, A., \& Kohlberg L. (1987). The measurement of moral judgment: Theoretical foundations and research validation (vol. 1, pp. 25-31). New York: Cambridge University Press.

Inayatullah, S. I., \& Inayatullah, S. (1997). The futures of democracy in Pakistan: A liberal perspective [Abstract]. Futures, 29 (10), pp. 955-970. Retrieved April 23, 2011, from http://www.sciencedirect.com.

Iqbal, A. (2004) Problems and prospects of higher educaton in Pakistan (Doctoral Dissertaion, University of Arid Agriculture, Rawalpindi, Punjab, Pakistan). Retrieved April 6, 2011, from Pakistan Research Repository online database. 
Khalid, T. (2004) Islamization in Pakistan: A political and constitutional study from 1947-1988 (Doctoral dissertation, University of Karachi, Karachi, Sind, Pakistan). Retrieved April 3, 2011, from Pakistan Research Repository online database.

Lind, G. (1978). Wie misst man moralisches Urteil? Probleme und alternative Möglichkeiten der Messung eines komplexen Konstrukts. In G. Portele, ed., Sozialisation und Moral. Weinheim: Beltz, pp. 171-201. Retrieved February 17, 2011, from http://www.uni-konstanz.de/ag-moral/pdf/Lind-1978_MUTin-Portele.pdf.

Lind, G. (1982). Experimental questionnaires: A new approach to personality research. A. Kossakowski \& K. Obuchowski, eds., Progress in psychology of personality, pp. 132-144. Amsterdam, NL: North-Holland. Retrieved March 22, 2011 from http://www.uni-konstanz.de/ag-moral/pdf/Lind1980_ExpQuest.pdf.

Lind, G. (1985). The theory of moral-cognitive development: a socio-psychological assessment. In G. Lind, H.A. Hartmann \& R. Wakenhut, Eds., Moral Development and the Social Environment. Studies in the Psychology and Philosophy of Moral Judgment and Education. Chicago: Precedent Publishing, pp. 21-53. Retrieved February 15, 2011, from http://www.unikonstanz.de/ag-moral/pdf/Lind-1985_et-al-Moral-Development.pdf.

Lind, G. (1986). Cultural differences in moral judgment competence? A study of West and East European university students. Behavior Science Research 20, pp. 208-225. Retrieved April 23, 2011, from http://www.uni-konstanz.de/agmoral/pdf/Lind-1986_Cultural-Difference.pdf.

Lind, G. (2000a). Review and appraisal of the moral judgment test (MJT). University of Konstanz. Retrieved December 3, 2010, from http://www.unikonstanz.de/ag-moral/pdf/Lind-2000_MJT-Review-and-Appraisal.pdf.

Lind, G. (2000b). Moral regression in medical students and their learning environment. Revista Brasileira de Educacao Médica 24(3), 24-33. Retrieved April 22, 2011, from http://www.uni-konstanz.de/ag-moral/pdf/Lind2000_Moral_Regression_in_Medical_Students.pdf.

Lind, G. (2000c). The Importance of Role-Taking Opportunities for Self-Sustaining Moral Development. Journal of Educational Research, 10, 9-15. Retrieved April 22, 2011 from http://www.uni-konstanz.de/ag-moral/pdf/Lind2000_Selfsustaining-moral-development.pdf. 
Lind, G. (2008). The Meaning and measurement of moral judgment competence: A dual-aspect model. In Fasko, Daniel, Jr. \& Willis, Wayne, eds. (2008). Contemporary philosophical and psychological perspectives on moral development and education, pp. 185-220.

Creskill, Hampton Press, Retrieved January 20, 2011, from http://www.unikonstanz.de/ag-moral/pdf/Lind-2008_Meaning-Measurement.pdf

Lupu, L. (2009). Moral, lernumwelt und religiosität:Die entwicklung moralischer urteilsfähigkeit bei studierenden in Rumänien in abhängigkeit von verantwortungsübernahme und religiosität. [English Abstract], (Doctoral dissertation, University of Konstanz, Germany). Retrieved April 24, 2011, from http://kops.ub.uni-konstanz.de/handle/urn:nbn:de:bsz:352-opus-95865.

Nowak, E. \& Lind, G., (2009) Mis-educative martial law: The fate of free discourse and the moral judgment competence of Polish university students from 1977 to 1983. Based on the paper presented at the annual conference of the Association for Moral Education in New York, 2007. Retrieved April 20, 2011, from http://www.uni-konstanz.de/ag-moral/pdf/Nowak-Lind-2009_Miseducative_law.pdf

Saeidi-Parvaneh, S. (2011). Moral, bildung und religion im Iran: Zur bedeutung universitärer bildung für die entwicklung moralischer urteils- und diskursfähigkeit in einem religiös geprägten land. [English Abstract], (Doctoral dissertation, University of Konstanz, Germany). Retrieved April 24, 2011, from http://kops.ub.uni-konstanz.de/handle/urn:nbn:de:bsz:352-opus131079

Schillinger-Agati, M.,_\& Lind, G. (2003). Moral Judgement Competence in Brazilian and German University Students. Paper presented at the Annual Meeting of the American Education Research Assotiation. Retrieved April 3, 2011, from http://www.uni-konstanz.de/ag-moral/pdf/Schillinger-Lind-2003_moraldevelopment-Brazil.pdf.

Shahzad, S. (2007). A study to investigate the quality of education at intermediate level in Punjab (Doctoral dissertation, University of Arid Agriculture, Rawalpindi, Punjab, Pakistan). Retrieved April 6, 2011, from Pakistan Research Repository online database.

The Constitution of the Islamic Republic of Pakistan, Article 227-1, Part IX, (2010). Retrieved April 24, 2011, from http://www.na.gov.pk/publications/ constitution.pdf. 
66 I Abdul Wahab Liaquat

Willgerodt, M. A., Kataoka-Yahiro, M. Kim, E., \& Ceria, C. (2005). Issues of instrument translation in research on Asian immigrant populations. Journal of Professional Nursing, 21, 231-239. 
Abdul Wahab Liaquat (Islamabad, Pakistan)

Moral Judgment Test (MJT) in Urdu: Translation and Validation

\begin{abstract}
The present study was conducted as part of a larger study that aimed to compare moral judgment competence and moral preferences among Pakistani students of public and private sector educational institutes and religious institutes and also to measure the pattern of development of moral judgment competence of students within these institutes. The validation study completed in two phases, during the 1st phase data were collected from the students of grade 8 to 16 from public sector schools and colleges of Rawalpindi city. Very low mean c-score was observed $(M=13.60, S D=9.05)$, the test came out to be valid on preference hierarchy criterion but its validity on the cognitive-affective parallelism and Quasi- simplex structure criteria could not be established due to low c-scores of the sample. In the second phase an additional sample from one private sector and two public sector universities was collected. The analysis of the combined sample $(\mathrm{N}=246)$ showed no significant improvement of c-scores $(\mathrm{M}=13.94, \mathrm{SD}=9.53)$. The test meets well the preference hierarchy criterion but on the other two criteria results remain inconclusive due to low variance in the sample. The low c-scores are explained on the basis of three assumptions; (1) poor quality of education, (2) dogmatic religiosity, and (3) weak and instable political structure of Pakistani society.
\end{abstract}

Keywords. Moral Judgment Competence, cognitive-affective parallelism, preference hierarchy, Quasi- simplex structure, validation study, dogmatic religiosity, political structure of Pakistani society, poor quality of education

Author. Mr. Abdul Wahab Liaquat (M. Sc. Applied Psychology) is a lecturer in Psychology at Government Postgraduate College, Asghar Mall, Rawalpindi, Pakistan. He is currently doing MS (Educational Psychology) at International Islamic University, Islamabad, Pakistan. The present study is part of his dissertation research.

Contact Address. Correspondence concerning this article should be addressed to: Abdul Wahab Liaquat. Email: wahabliaqat@yahoo.com. Cell Phone: 92-334-5005339.

Citations. Reference this paper as: Wahab Liaquat, A. (2011). Moral Judgment Test (MJT) in Urdu: Translation and Validation. Ethics in Progress Quarterly, Volume 2, Issue 2, pp. 47-67, available online at ethicsinprogress.org. 